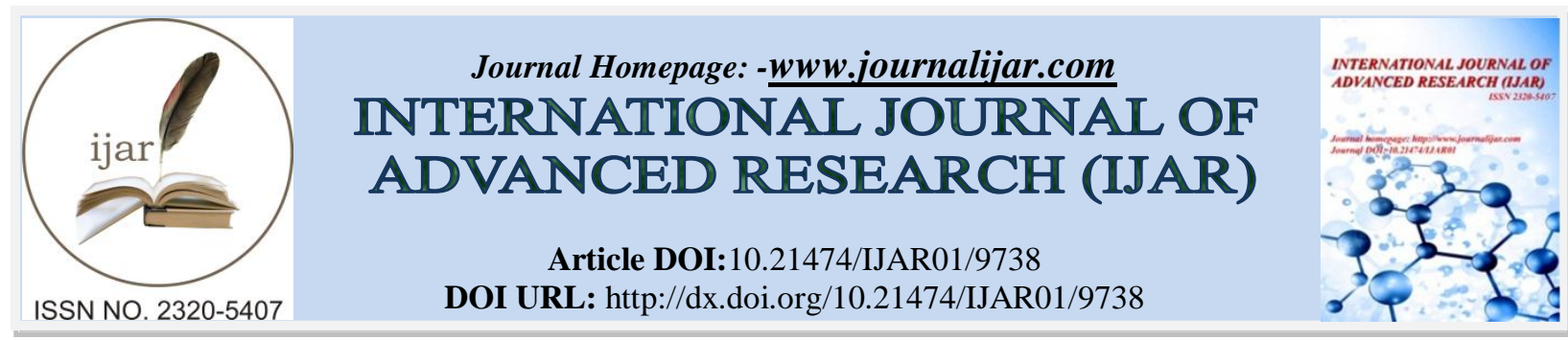

RESEARCH ARTICLE

\title{
COMPARATIVE EVALUATION OF MICROLEAKAGE AND COMPRESSIVE STRENGTH OF GLASS IONOMER CEMENT TYPE IX, ZIRCONOMER IMPROVED AND CENTION N - AN IN VITRO STUDY.
}

\section{Dr. Talat $\mathrm{Naz}^{1}$, Dr. Deepti Jawa Singh ${ }^{2}$, Dr. Rani Somani ${ }^{3}$ and Dr. Shipra Jaidka ${ }^{4}$.}

1. Post graduate - Department of Pedodontics and Preventive Dentistry, Divya Jyoti College of Dental Sciences and Research, Address - 36 A, Dr. Sudhir Bose Road, Kaiser Court Bd, Khidderpore, Kolkata - 700023, West Bengal, India.

2. Professor, Department of Pedodontics and Preventive Dentistry, Divya Jyoti College of Dental Sciences and Research, Address - A-28, Defence Colony, Mawana Road, Meerut (UP) 250001, India.

3. Professor and Head of Department, Department of Pedodontics and Preventive Dentistry, Divya Jyoti College of Dental Sciences and Research, Address - G-3, 617, Sector - 1, Vaishali, Ghaziabad, U.P - 201010, India.

4. Professor, Department of Pedodontics and Preventive Dentistry, Divya Jyoti College of Dental Sciences and Research, Address - L-44 Pallavpuram Phase 2, Meerut, India.

\section{Manuscript Info}

(..........................

Manuscript History

Received: 12 July 2019

Final Accepted: 14 August 2019

Published: September 2019

Key words:-

Cention N, Zirconomer Improved,

isofiller, transgranular fracture.

\section{Abstract}

Context: Restorative dentistry is a blend of art and science. Newer restorative materials like Cention $\mathrm{N}$ and Zirconomer Improved are giving a challenge to conventional restorative materials.

Aims: To evaluate and compare the microleakage and compressive strength of GIC type IX, Zirconomer Improved and Cention N using stereomicroscope and universal testing machine.

Study design: For microleakage evaluation, 45 non carious extracted premolars divided into three groups were restored with GIC type IX, Zirconomer Improved and Cention $\mathrm{N}$ respectively. Post thermocycling they were immersed in mythelene blue dye for 24 hours. Sectioning was done and viewed under stereomicroscope for scoring by Vinay $\mathrm{S}$ and Shivanna V. For compressive strength evaluation, 45 standardized autoclavable moulds were taken and divided into three groups each, which were then restored with GIC type IX, Zirconomer Improved and Cention $\mathrm{N}$ respectively. Thermocycling was done and the pellets were stored in distilled water for 24 hours and subjected to compressive strength testing in universal testing machine. The data was statistically analyzed and results were obtained.

Statistical analysis: One Way-Anova and Tukey's Post Hoc Test Was Used for Multiple Group Comparisons.

Result: Cention N had the least microleakage followed by Zirconomer Improved and GIC type IX. Compressive strength was highest in Cention $\mathrm{N}$ followed by Zirconomer Improved and least with GIC type IX.

Conclusion: Cention $\mathrm{N}$ can be recommended as a permanent restorative material on account of good compressive strength and less microleakage.

\section{Corresponding Author:-Dr. Talat Naz.}

Address:-Post graduate - Department of Pedodontics and Preventive Dentistry, Divya Jyoti College of Dental Sciences and Research, Address - 36 A, Dr. Sudhir Bose Road, Kaiser Court Bd, Khidderpore, 


\section{Introduction:-}

Dental caries is an infectious microbiologic disease of the teeth that results in localized dissolution and destruction of the calcified tissues. Caries activity, as evidenced by demineralization and loss of tooth structure varies, and the course of individual lesion is not always predictable. Once caries occurs it has to be restored. Restoration of the tooth structure is essential for the proper functioning of the teeth and prevention of further loss of tooth structure. The ideal restorative material should have good compressive strength, diametral tensile strength, shear bond strength and least microleakage for the success and longevity of a restoration. ${ }^{1}$

For centuries the quest for an ideal biomimetic material has been the holy grail of dental restorative field. Hence newer materials like Zirconomer Improved and Cention $\mathrm{N}$ have been introduced to meet the demands of an ideal biomimetic material. Recently in the year 2014, because of the high strength and esthetic appearance, Zirconia $\left(\mathrm{ZrO}_{2}\right)$ was infused in GIC (ZIRCONOMER), in an attempt to address all the issues that have plagued the conventional glass ionomer so far. Because of its high strength it is also called white amalgam. ${ }^{2}$

Another novel restorative material, Cention N, introduced in 2016 which like compomer is dual cure as it sets by both self curing and light-curing. Cention $\mathrm{N}$ is an "alkasite" restorative material which refers to a new category of basic filling material. This new category utilizes an alkaline filler, capable of releasing acid-neutralizing ions. It also includes a special patented filler (isofiller) which acts as a shrinkage stress reliever minimizing the shrinkage force. ${ }^{3}$ The newer restorative material needs to have the physical and chemical properties that are comparable or superior to our gold standard conventional GIC to be accepted as a permanent restorative material especially in pediatric dentistry. Keeping this in mind, the present study was done with the aim to comparatively evaluate the microleakage and compressive strength of GIC type IX, Zirconomer Improved and Cention N.

\section{Material and Method:- Microleakage analysis}

A sample size of 45 teeth was taken after confirming the statistical validity for the study. For microleakage evaluation, 45 non carious human premolar teeth extracted for orthodontic purpose were taken. The teeth were scaled and autoclaved. The storage medium for the entire study was distilled water. Standardized class V cavities ( 3 mm wide X $2 \mathrm{~mm}$ high X $1.5 \mathrm{~mm}$ deep) were made, $1 \mathrm{~mm}$ above the cementoenamel junction on the buccal/lingual surfaces of all the teeth in the selected sample. The samples were randomly divided into three groups with color coding namely, group A as GIC Type IX (purple), group B as Zirconomer Improved (green) and group C as Cention $\mathrm{N}$ (red) respectively [Flowchart 1]. All the samples were restored with the respective restorative material according to the manufacturer's instructions. Any excess material was removed with a yellow coated bur (ISO 160/014) in a slow speed hand piece. The samples were then stored for 24 hours in distilled water. Later on thermocycling was done to simulate oral conditions. Then the samples were prepared for dye immersion by coating each sample with finger nail varnish, with the exception of a $0.5-1.0 \mathrm{~mm}$ window around the restoration margins and sealing the apices with sticky wax. The teeth were immersed in $2 \%$ methylene blue dye for 48 hours. Thereafter the samples were sectioned longitudinally in a bucco-lingual direction. Out of 90 sections obtained from 45 teeth, only 45 sections were selected which were complete and not fractured or chipped off. The microleakage was assessed by viewing all the treatment groups under stereomicroscope at a magnification of $40 \mathrm{X}$. The scoring criteria for the microleakage assessment were followed according to Vinay S and Shivanna V (2010). [Figure 1(A-E)]

1. $0=$ No dye penetration.

2. 1 = Dye penetration up to $1 / 3^{\text {rd }}$ cavity depth

3. 2 = Dye penetration up to $2 / 3^{\text {rd }}$ cavity depth

4. $3=$ Dye penetration to full depth of cavity

5. $4=$ Dye penetration onto axial wall of cavity.

\section{Compressive strength analysis}

45 standardized moulds were made of $5 \mathrm{~mm}$ diameter and $6 \mathrm{~mm}$ height. Then they were divided into three groups with color coding namely, group I as GIC Type IX (purple), group II as Zirconomer Improved (green) and group III as Cention N (red) respectively [Flowchart 2]. All the moulds were restored with the respective restorative material according to the manufacturer's instructions. After the setting of the restorative material, the restorative material pellets were taken out from the moulds, thermocycling was done for 500 cycles at 55 degree celcius and 5 degree 
celcius with a dwell time of 30 seconds in each bath and a transfer time of 30 seconds and stored in distilled water for 24 hours in their respective labelled sterile containers to allow the restoration to set completely. Then they were subjected to compressive strength determination using Instron Universal Testing Machine. [Figure 2]

\section{Statistical analysis:-}

The SPSS 11.0 and Systat 8.0 Statistical software were used for the analysis. ONE WAY-ANOVA and TUKEY'S POST HOC test was used for multiple group comparisons. Results are expressed as Mean \pm SD. For all the tests, a P-value of 0.05 or less was used for statistical significance. [Table 5, Table 6]

\section{Results:-}

Microleakage evaluation: The mean value of microleakage was lowest in Group C (Cention N) 0.80, followed by Group B (Zirconomer Improved) 1.47 and highest in Group A (GIC Type IX) 2.87. [Table 1, Graph 1]

All intercomparisions between the mean microleakage values of various groups was found to be highly significant. [Table 2, Table 5]

Compressive strength evaluation: The mean value of compressive strength was highest in Group III (Cention N) 301.20 MPa followed by Group II (Zirconomer Improved) $150.60 \mathrm{MPa}$ and least with Group I (GIC type IX) 99.0 MPa. [Table 3, Graph 2]

All intercomparisions between the mean compressive strength values of various groups was found to be highly significant. [Table 4, Table 6]

\section{Discussion:-}

The Glass Ionomer Cement was introduced by Wilson and Kent in 1972 and since then it has been widely used because of its unique properties, such as anti-carcinogenic character, lack of exothermic polymerization, excellent adhesion to dentin, almost same thermal expansion as that of tooth, satisfactory biocompatibility. One of the major drawbacks of conventional GIC is its weak mechanical properties like brittleness, low strength, and toughness. To overcome the drawbacks, the conventional GIC has undergone innumerable changes and inclusions in its properties and composition. ${ }^{4}$

Cention $\mathrm{N}$ had the least microleakage among various group. The reason may be because Cention $\mathrm{N}$ has a special patented filler isofiller, which is partially functionalized by silanes which acts like a spring, expanding slightly as the forces between the fillers grow during polymerization. ${ }^{3,5}$ Hence, it pushes the material towards cavity walls which further leads to close adaptation and thus reduces the microleakage. Study done by Soumita Samanta, Utpal Kumar, Aditya Mitra (2017) on microleakage in class V cavity restored with flowable Composit resin, GIC and Cention $\mathrm{N}$ also found that Cention $\mathrm{N}$ exhibited the lowest microleakage. ${ }^{6}$

Compressive strength of Cention $\mathrm{N}$ was found to be highest because of the presence of UDMA particles in the monomer matrix which is less elastic and provides stiffness to the matrix, thus becoming highly resistant to stresses generated in the oral cavity. ${ }^{7}$ The cyclic aliphatic structure of aromatic aliphatic UDMA ensures stability and increased mechanical strength. A study was done by Paromita Mazumdar, Abiskrita Das and Chiranjan Guha (2018) on hardness of different restorative materials mainly GIC Type II, Cention N, Nanohybrid Composite Resin and Silver Amalgam. They found that Cention $\mathrm{N}$ had the highest microhardness values among all the experimental groups. $^{8}$ (Figure 2)

The mean microleakage of Zirconomer Improved was found to be more than Cention $\mathrm{N}$ but less than GIC Type IX. Zirconomer Improved has zirconia fillers which is an unstable compound and hence changes its phase from monoclinic to tetragonal and then to cubic and vice versa thereby increasing in volume counteracting the volumetric shrinkage expressed during polymerization. ${ }^{9}$ Study done by Walia $\mathbf{R}$ et al in 2016 on micoleakage of Zirconomer and Giomer where he stated that microleakge of Zirconomer was less than that of Giomer. ${ }^{10}$

Compressive strength of Zirconomer Improved was found to be higher than GIC type IX. Pure Zirconia is unstable in nature which even after addition of Yttrium remains metastable so to further stabilize it aluminium is added as an impurity in the Zirconomer powder. These impurities of alumina occupy the edges of zirconia and provide an increase in transgranular fracture mode which means in case a crack has been created either because of internal 
stress or external masticatory load; it will appear only at the border of the transgranular structure of aluminium stabilized Zirconia filler. In response to stress, Zirconia changes its shape to monoclinic and thus expands slightly and closes the propagation of cracks thus making it a stiffer structure having good compressive strength. ${ }^{9,11}$ A study was done by Hind P Bhatia (2017) on the sorption, solubility and compressive strength of three different glass ionomer cements mainly type IX glass ionomer cement, silver-reinforced glass ionomer cement, and zirconiareinforced glass ionomer cement, where they stated that Zirconomer had the highest compressive strength values. ${ }^{1}$

The mean microleakage of GIC Type IX was found to be highest when compared to Cention N and Zirconomer Improved where as the mean compressive strength of GIC Type IX was found to be lowest.

GIC Type IX has high elastic modulus and hence lower elasticity when compared to fillers in Cention N and Zirconomer Improved. These lesser elastic fillers do not neutralize enough shrinkage stress generated within the matrix of GIC Type IX and hence do not counteract the volumetric shrinkage sufficiently during polymerization. Moreover, they are not so stiff to counteract enough stresses or occlusal load which might lead to fracture of the restoration because of lesser compressive strength. Study done by Amish Diwanji et al in $\mathbf{2 0 1 4}$ on microleakage of three restorative glass ionomer cements where he stated that Fuji IX showed the maximum leakage, followed by LC II and the least was observed in $\mathrm{KN} 100 .{ }^{12}$

\section{Conclusion:-}

Within the limitation of this in vitro study it was concluded that the mean microleakage score was minimum in Cention N (IVOCLAR), followed by Zirconomer Improved (SHOFU) and was maximum in GIC TYPE IX (FUJI IX). The mean compressive strength was highest in Cention N (IVOCLAR), followed by Zirconomer Improved (SHOFU) and lowest in GIC Type IX (FUJI IX). Hence, Cention N can be recommended as a permanent restorative material to achieve high success and longevity of a restoration.

\section{Financial support and sponsorship}

Nil.

\section{Conflicts of interest}

There are no conflicts of interest.

\section{Data availability}

The research data used to support the findings of this study are included within the manuscript file. Any additional information is not available as the study is done on recently introduced restorative materials.

\section{Acknowledgement regarding "Comparative evaluation of microleakage and compressive strength of GIC} type IX, Zirconomer Improved and Cention N - An in vitro study"

1. We would like to thank "Divya Jyoti College of Dental Sciences \& Research" for allowing and constantly supporting throughout the study.

2. We would like to thank "Apex Assessment Labs Pvt. Ltd" for helping in evaluation of compressive strength of the materials used in the study.

3. We would also like to thank "Department of Oral and Maxillofacial Pathology \& Oral Microbiology", Subharti Dental College, Swami Vivekanand Subharti University, for helping in evaluation of microleakage of the materials used in the study.

4. Last but not the least, a heartiest thanks goes to Dr. Wasim Hussain for his valuable support throughout the study. 


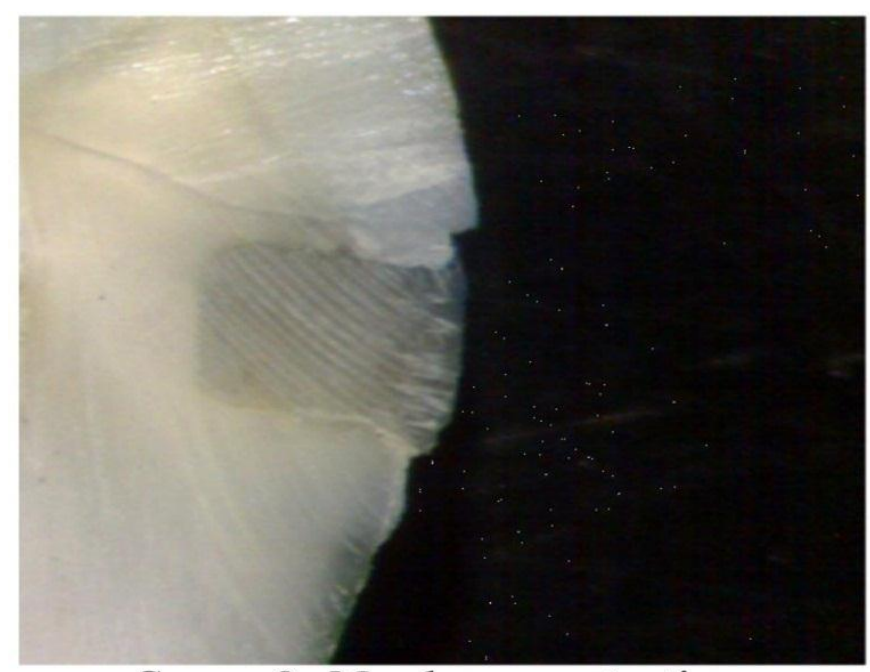

Score O- No dye penetration

Figure 1 (A):-

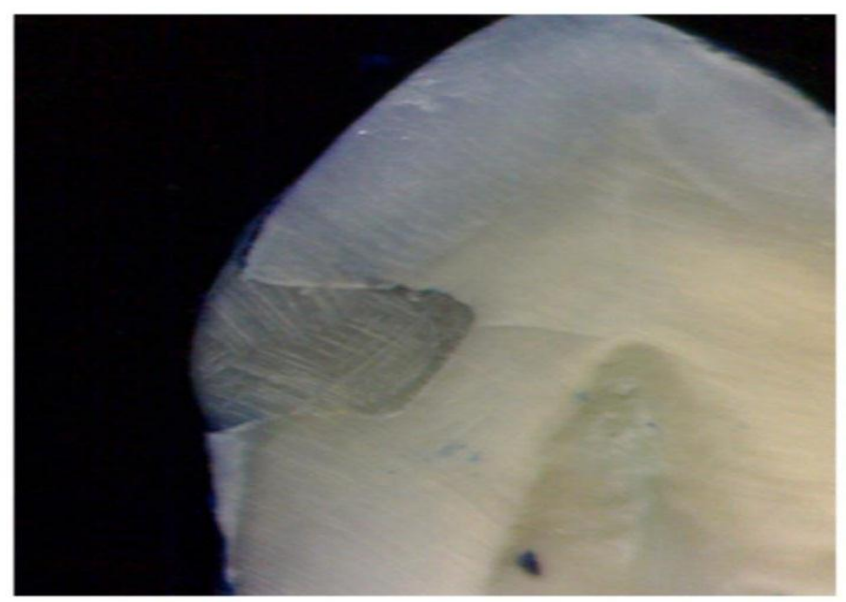

Score 1 - Dye penetration up to $1 / 3$ rd cavity depth

Figure 1 (B):-

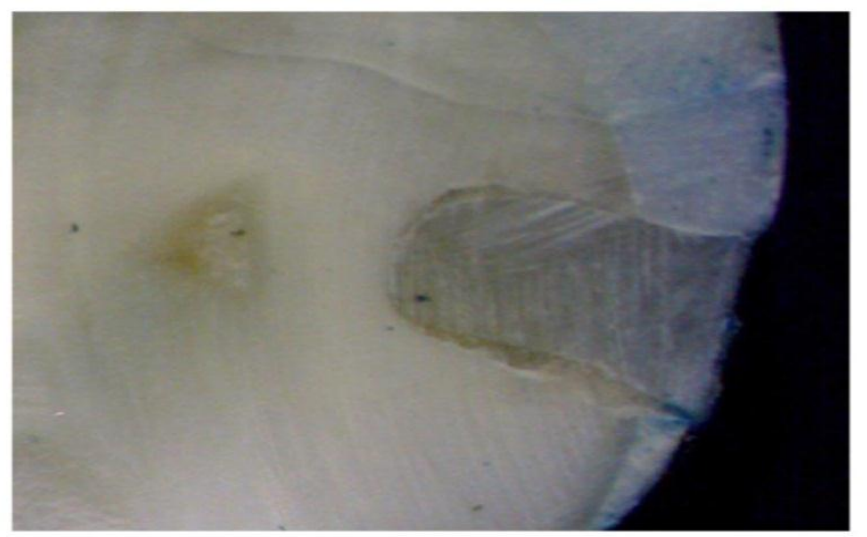

Score 2- Dye penetration up to $2 / 3$ rd cavity depth

Figure 1 (C):- 


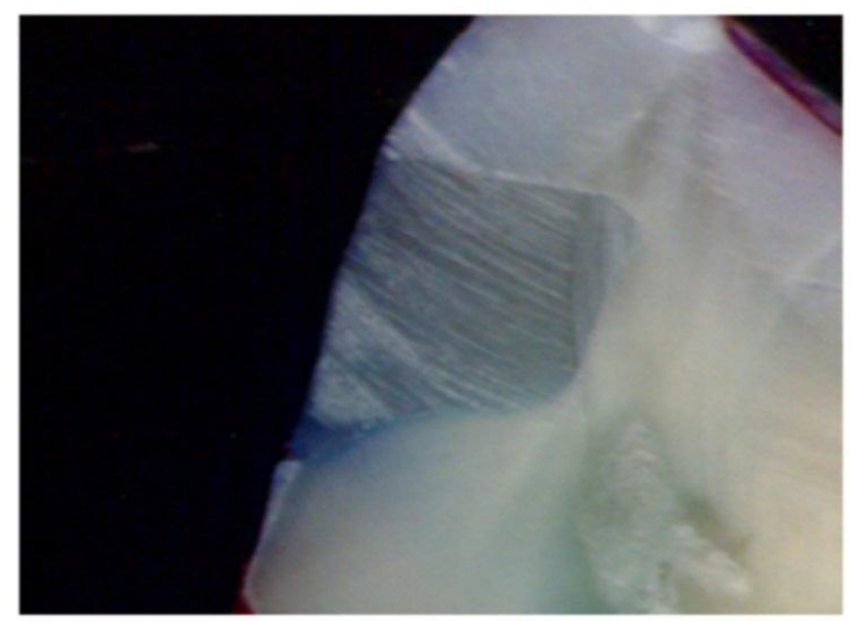

Score 3- Dye penetration to full depth of cavity

Figure 1 (D):-

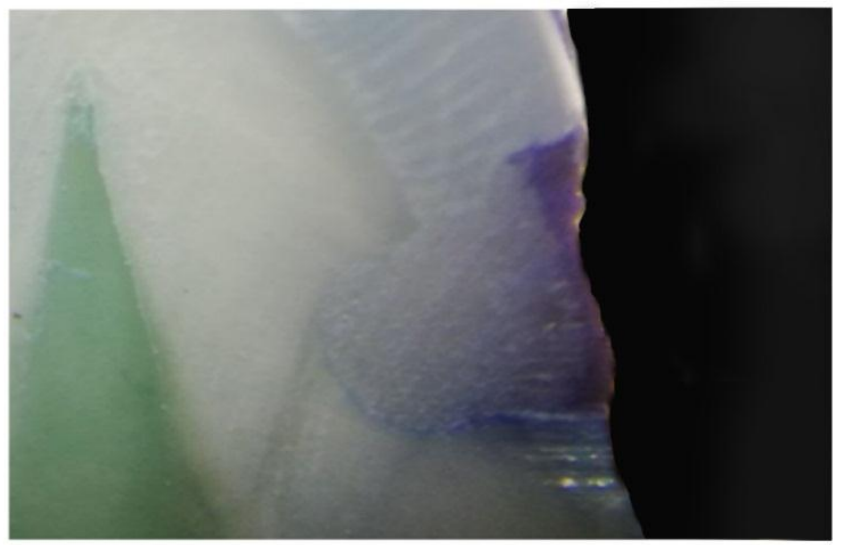

Score 4- Dye penetration onto axial wall of cavity

Figure 1 (E):-

Figure 1 (A-E):-Scoring Criteria ForMicroleakage Evaluation 


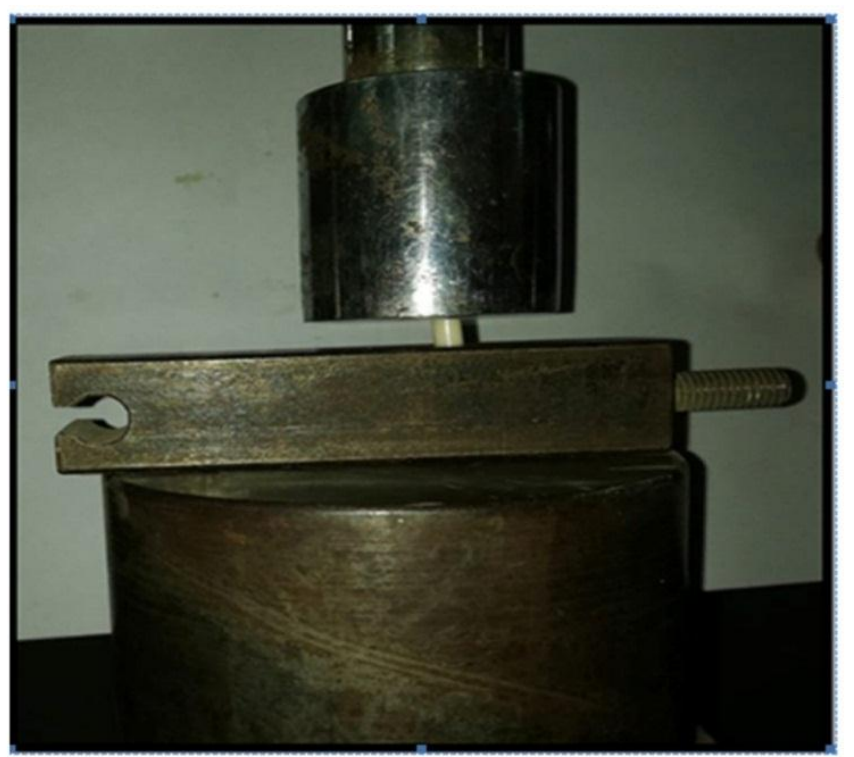

Figure 2:-Compressive Strength Testing In Universal Testing Machine

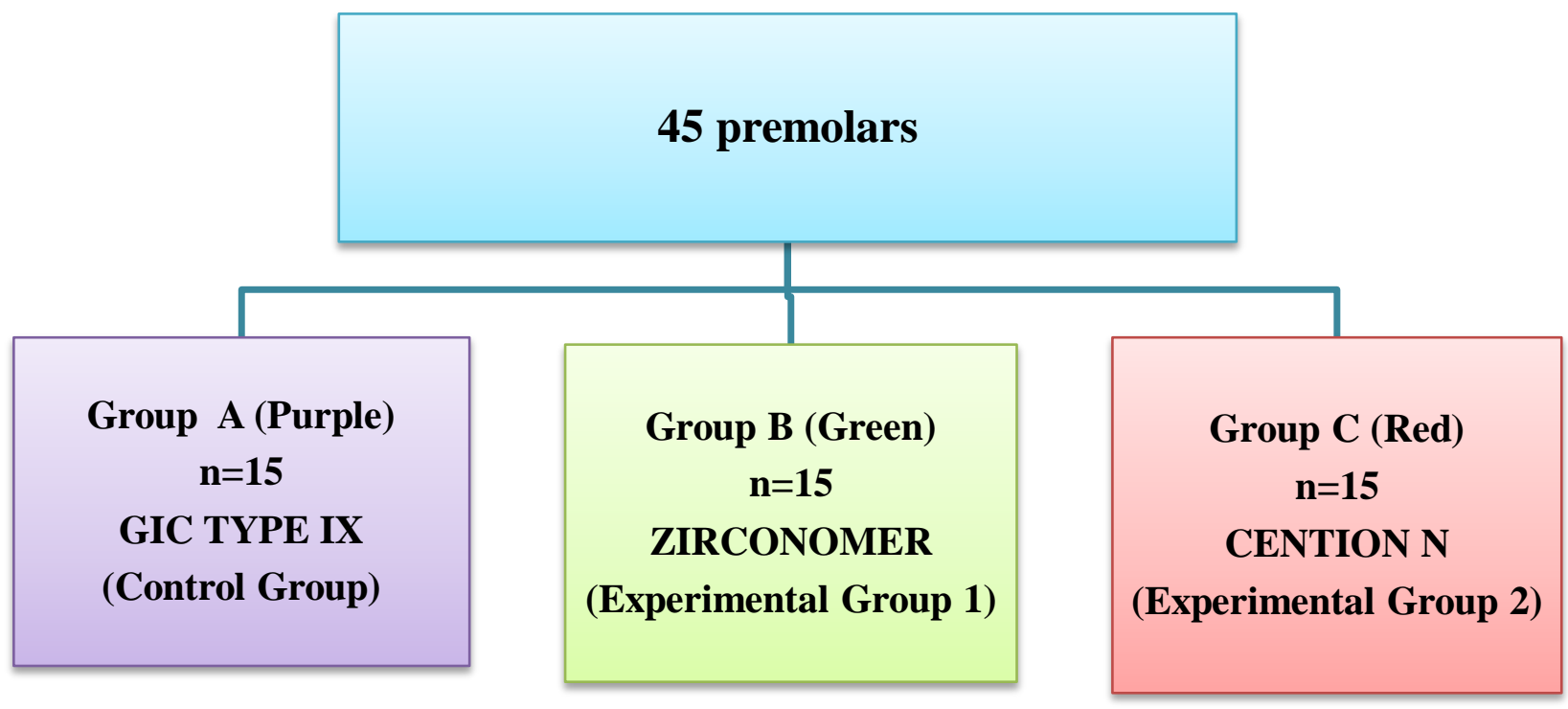

Flowchart 1:-Division of samples for microleakage evaluation 


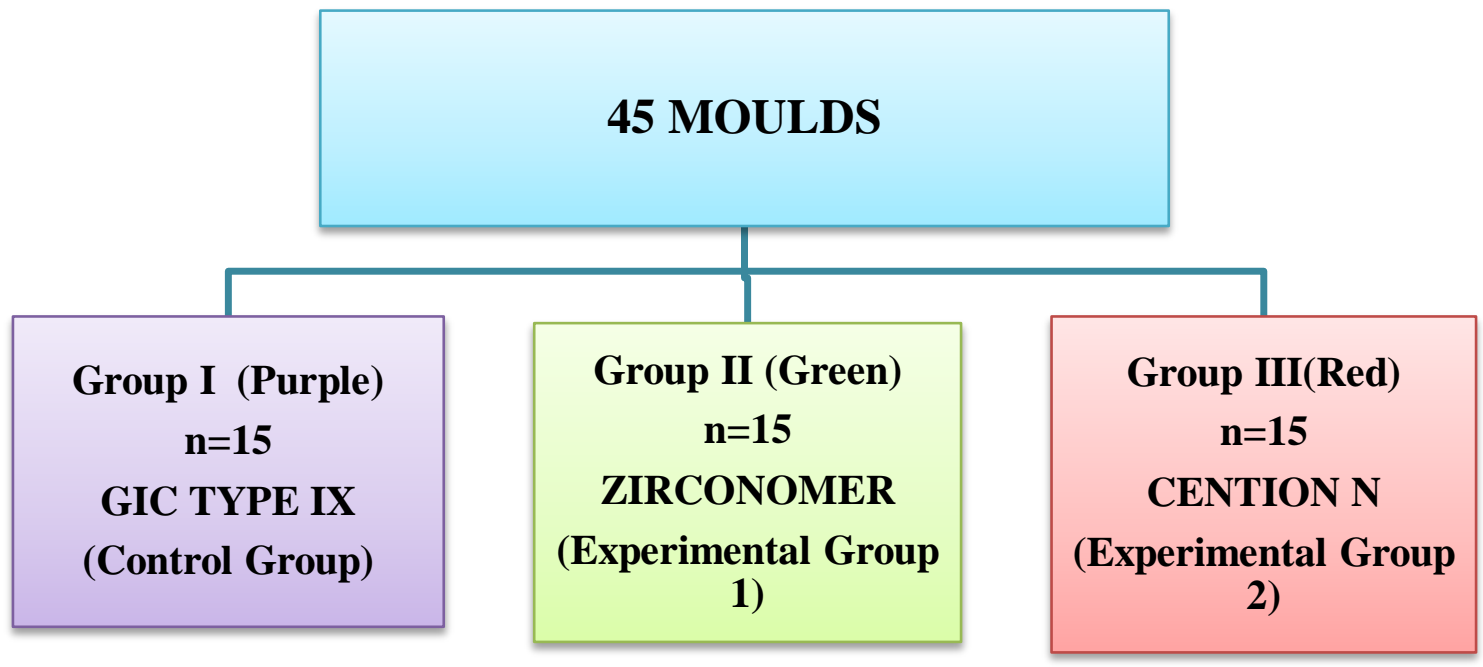

Flowchart 2:-Division of Moulds

\begin{tabular}{|c|c|c|c|c|}
\hline Group & $\begin{array}{c}\text { N } \\
\text { (Sample sie) }\end{array}$ & Mean & Std. Deviation & Std. Error Mean \\
\hline $\begin{array}{c}\text { Group A } \\
\text { (GIC type IX) }\end{array}$ & 15 & 2.87 & 0.915 & 0.236 \\
\hline $\begin{array}{c}\text { Group B } \\
\text { (Zirconomer Improved) }\end{array}$ & 15 & 1.47 & 0.640 & 0.165 \\
\hline $\begin{array}{c}\text { Group C } \\
\text { (Cention N) }\end{array}$ & 15 & 0.80 & 0.561 & 0.145 \\
\hline
\end{tabular}

Table 1:-Mean Values of Microleakage in Various Groups

\begin{tabular}{|c|c|c|c|c|c|c|}
\hline (I) Group & (J) Group & $\begin{array}{c}\text { Mean Difference } \\
\text { (I-J) }\end{array}$ & $\begin{array}{c}\text { Std. } \\
\text { Error }\end{array}$ & p value & \multicolumn{2}{|c|}{ 95\% Confidence Interval } \\
\cline { 4 - 7 } & & 1.400 & 0.263 & $0.000^{*}$ & Lower Bound & Upper Bound \\
\hline \multirow{2}{*}{ A } & B & 2.067 & 0.263 & $0.000^{*}$ & 1.41 & 2.06 \\
\cline { 2 - 7 } & C & -1.400 & 0.263 & $0.000^{*}$ & -2.06 & -0.74 \\
\cline { 2 - 7 } & A & 0.667 & 0.263 & $0.046^{*}$ & 0.01 & 1.32 \\
\hline \multirow{2}{*}{ C } & C & -2.067 & 0.263 & $0.000^{*}$ & -2.72 & -1.41 \\
\cline { 2 - 7 } & A & -0.667 & 0.263 & $0.046^{*}$ & -1.32 & 0.00 \\
\hline
\end{tabular}

Table 2:-Inter Comparison of Microleakage of Various Groups

$\mathrm{p}$ value $<0.05=$ Significant $*$

$\mathrm{p}$ value $>0.05=$ Non Significant $* *$

Group A - GIC type IX

Group B - Zirconomer improved

Group C - Cention N

\begin{tabular}{|c|c|c|c|c|}
\hline Group & $\begin{array}{c}\text { N } \\
\text { (Sample size) }\end{array}$ & Mean & Std. Deviation & Std. Error Mean \\
\hline $\begin{array}{c}\text { Group I } \\
\text { (GIC type IX) }\end{array}$ & 15 & 99.00 & 5.000 & 1.291 \\
\hline $\begin{array}{c}\text { Group II } \\
\text { (Zirconomer Improved) }\end{array}$ & 15 & 150.60 & 4.032 & 1.041 \\
\hline Group III & 15 & 301.20 & 6.774 & 1.749 \\
\hline
\end{tabular}


(Cention N)

Table 3:-Mean Values of Compressive Strength in Various Groups

\begin{tabular}{|c|c|c|c|c|c|c|}
\hline \multirow[t]{2}{*}{ (I) Group } & \multirow[t]{2}{*}{ (J) Group } & \multirow{2}{*}{$\begin{array}{c}\text { Mean } \\
\text { Difference (I-J) }\end{array}$} & \multirow{2}{*}{$\begin{array}{l}\text { Std. } \\
\text { Error }\end{array}$} & \multirow[t]{2}{*}{$\mathrm{p}$ value } & \multicolumn{2}{|c|}{$95 \%$ Confidence Interval } \\
\hline & & & & & Lower Bound & Upper Bound \\
\hline \multirow[t]{2}{*}{ I } & II & -51.600 & 1.968 & $0.000 *$ & -56.51 & -46.69 \\
\hline & III & -202.200 & 1.968 & $0.000 *$ & -207.11 & -197.29 \\
\hline \multirow[t]{2}{*}{ II } & $\mathrm{I}$ & 51.600 & 1.968 & $0.000 *$ & 46.69 & 56.51 \\
\hline & III & -150.600 & 1.968 & $0.000 *$ & -155.51 & -145.69 \\
\hline \multirow[t]{2}{*}{ III } & $\mathrm{I}$ & 202.200 & 1.968 & $0.000 *$ & 197.29 & 207.11 \\
\hline & II & 150.600 & 1.968 & $0.000 *$ & 145.69 & 155.51 \\
\hline
\end{tabular}

Table 4:-Inter Comparison of Compressive Strength of Various Groups

$\mathrm{p}$ value $<0.05=$ Significant $*$

$\mathrm{p}$ value $>0.05=$ Non Significant $* *$

Group I - GIC type IX

Group II - Zirconomer Improved

Group III - Cention N

\begin{tabular}{|c|c|c|c|c|c|c|}
\hline \multicolumn{7}{|c|}{ ANOVA } \\
\hline & & $\begin{array}{l}\text { Sum of } \\
\text { Squares }\end{array}$ & $\mathrm{df}$ & Mean Square & $\mathrm{F}$ & Sig. \\
\hline \multirow[t]{3}{*}{ Microleakage } & Between Groups & 33.378 & 2 & 16.689 & 32.055 & 0.000 \\
\hline & Within Groups & 21.867 & 42 & 0.521 & & \\
\hline & Total & 55.244 & 44 & & & \\
\hline
\end{tabular}

Table 5:-Comparison of Means of Microleakage in all groups

\begin{tabular}{|l|l|r|r|r|r|r|}
\hline \multicolumn{9}{|c|}{ ANOVA } & \multicolumn{1}{c|}{ F } & \multicolumn{1}{c|}{ Sig. } \\
\hline \multirow{2}{*}{$\begin{array}{l}\text { Compressive } \\
\text { Strength }\end{array}$} & Between Groups & 331138.800 & 2 & 165569.400 & $5.700 \mathrm{E} 3$ & 0.000 \\
\cline { 2 - 8 } & Within Groups & 1220.000 & 42 & 29.048 & & \\
\cline { 2 - 8 } & Total & 332358.800 & 44 & & & \\
\hline
\end{tabular}

Table 6:-Comparison of Means of compressive strength in all groups 


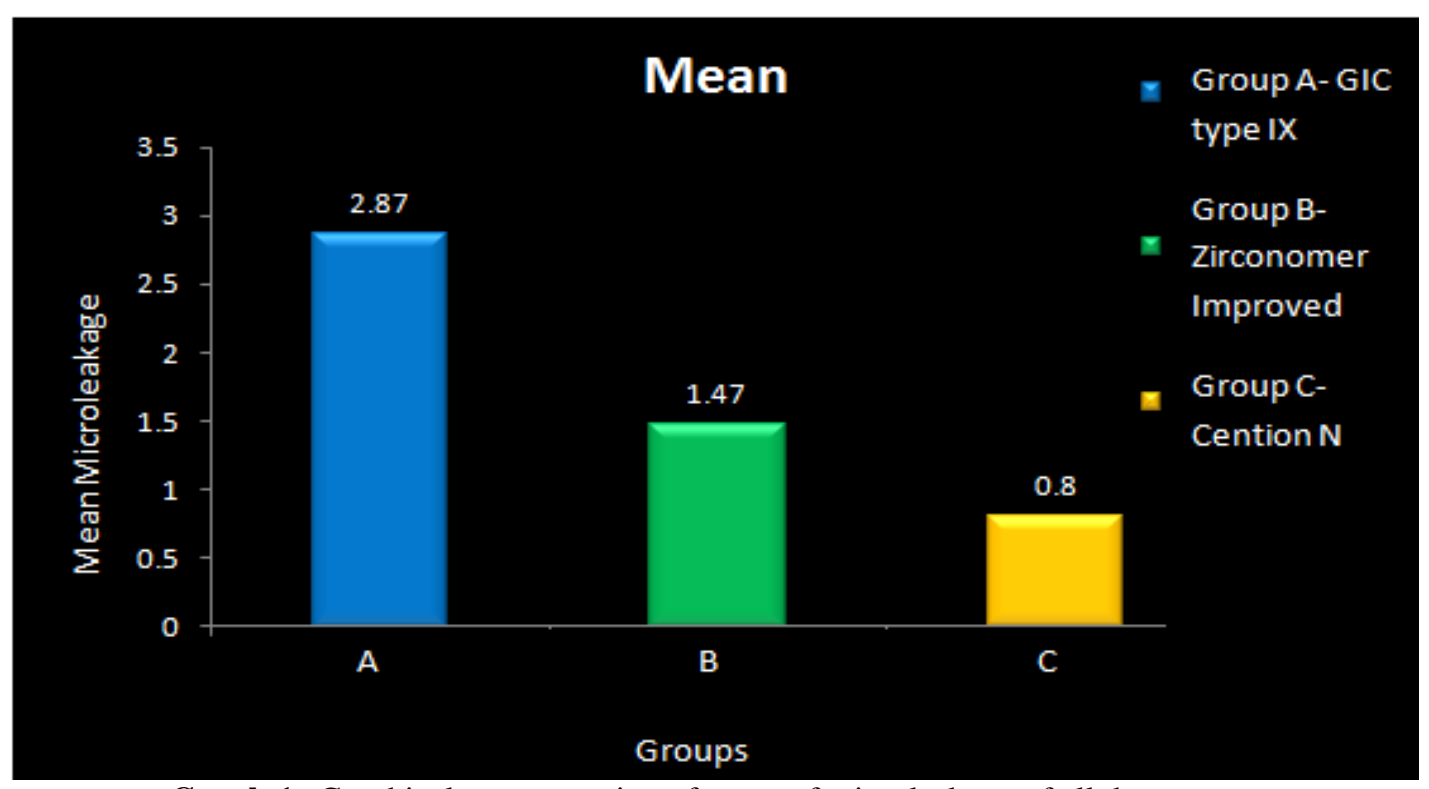

Graph 1:-Graphical representation of mean of microleakage of all the groups.

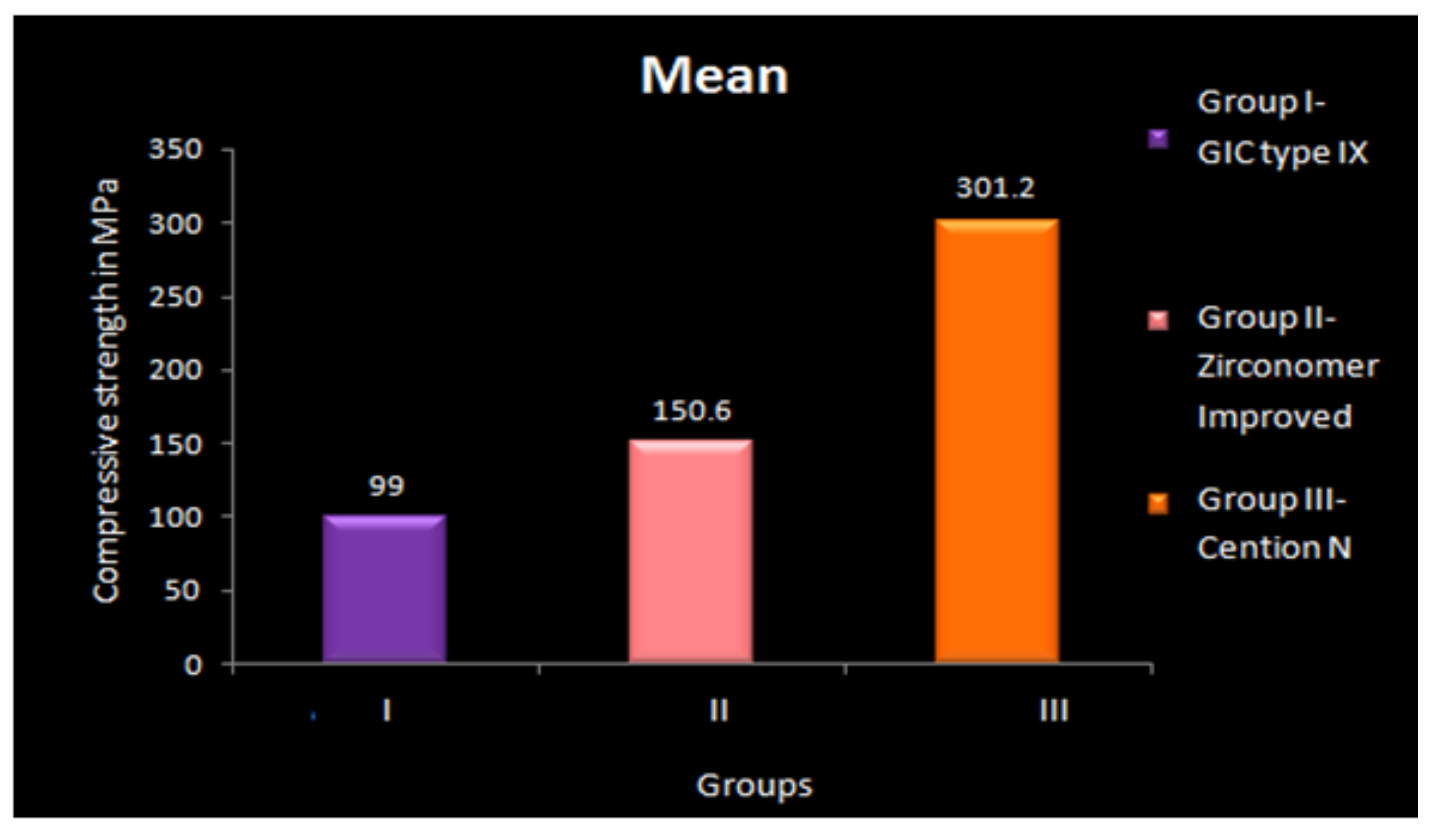

Graph 2:-Graphical representation of mean of compressive strength of all the groups.

\section{References:-}

1. Hind P Bhatia, Shivani Singh, Shveta Sood, Naresh Sharma. A Comparative Evaluation of Sorption, Solubility, and Compressive Strength of Three Different Glass Ionomer Cements in Artificial Saliva: An in vitro Study. Int J Clin Pediatr Dent 2017; 10(1):49-54.

2. Dr. Uday Kamath, Dr. Afna Salam. Fracture resistance of maxillary premolars with mod cavities restored with Zirconomer: An in vitrocomparative study. Int J Appli Dent Sci 2016; 2(2):77-80.

3. Dr. Jagvinder Singh Mann, Dr. Sunakshi Sharma, Dr. Sonal Maurya, Dr. Ashok Suman. Cention N: A Review. International Journal of Current Research. 2018; 10(5):69111-69112.

4. André M, Jane Clei O A, Rosa A, Paulo V R, Letícia B J. Compressive strength of glass ionomer cements using different specimen dimensions. Braz Oral Res. 2007 Jul-Sep; 21(3):204-8.

5. S. Deepak, M. S. Nivedhitha. Proximal contact tightness between two different restorative materials - An in vitro study. J Adv Pharm Edu Res 2017; 7(2):153-156. 
6. Soumita Samanta, Utpal Kumar Das, Aditya Mitra. Comparison of Microleakage In Class V Cavity Restored with Flowable Composite Resin, Glass Ionomer Cement and Cention N. International Journal of Interdisciplinary Research. 2017; 3(8):180-183.

7. Dr. Debolina Chowdhury, Dr. Chiranjan Guha, Dr. Priti Desai. Comparative evaluation of fracture resistance of dental Amalgam, Z350 Composite resin and Cention N restoration in class II cavity. IOSR Journal of Dental and Medical Sciences. 2018; 17(4):1.

8. Paromita Mazumdar, Abiskrita Das, Chiranjan Guha. Comparative evaluation of hardness of different restorative materials (restorative GIC, Cention N, Nano Hybrid Composite Resin and Silver Amalgam) - An in vitro study. Int J Adv Res. 2018; 6(3):826-832.

9. Nagy Abdulsamee Ahmed Hosny Elkhadem. Zirconomer and Zirconomer Improved (White Amalgams): Restorative Materials for the Future. Review. EC Dental Science. 2017, 15.4: 134-150.

10. Walia R, Jasuja P, Verma K G, Juneja S, Mathur A, Ahuja L. A comparative evaluation of microleakage and compressive strength of Ketac Molar, Giomer, Zirconomer, and Ceram-X: An in vitro study. J Indian Soc Pedod Prev Dent 2016; 34:280-4.

11. Dr. Chitharanjan Shetty, Dr. Vandana Sadananda, Prof. Dr. Mithra N. Hegde, Dr. Anish Kumar Lagisetti, Prof. Dr. Aditya Shetty, Dr. Tony Mathew, Prof. Dr. Shishir Shetty. Comparative Evaluation of Compressive Strength of Ketac Molar, Zirconomer, and Zirconomer Improved. J. Dent. Sci. 2017 June; 4(6):259-261.

12. Amish Diwanji, Vineet Dhar, Ruchi Arora, A Madhusadan, Ambika Singh Rathore. Comparative evaluation of microleakage of three restorative glass ionomer cements: An in vitro study. J Nat Sci Biol Med. 2014; 5(2):373377. 